NBER WORKING PAPER SERIES

\title{
WHY HAS THE U.S. FINANCIAL SECTOR GROWN SO MUCH? THE ROLE OF CORPORATE FINANCE.
}

\author{
Thomas Philippon \\ Working Paper 13405 \\ http://www.nber.org/papers/w13405 \\ NATIONAL BUREAU OF ECONOMIC RESEARCH \\ 1050 Massachusetts Avenue \\ Cambridge, MA 02138 \\ September 2007
}

I thank seminar participants at NYU and Duke University for their comments. The views expressed herein are those of the author(s) and do not necessarily reflect the views of the National Bureau of Economic Research.

(C) 2007 by Thomas Philippon. All rights reserved. Short sections of text, not to exceed two paragraphs, may be quoted without explicit permission provided that full credit, including $(\subset$ notice, is given to the source. 
Why Has the U.S. Financial Sector Grown so Much? The Role of Corporate Finance.

Thomas Philippon

NBER Working Paper No. 13405

September 2007, Revised January 2008

JEL No. E2,G2,G3,O16

\begin{abstract}
$\underline{\text { ABSTRACT }}$
The share of finance in U.S. GDP has been multiplied by more than three over the postwar period. I argue, using evidence and theory, that corporate finance is a key factor behind this evolution. Inside the finance industry, credit intermediation and corporate finance are more important than globalization, increased trading, or the development of mutual funds for explaining the trend. In the non financial sector, firms with low cash flows account for a growing share of total investment. I build a simple equilibrium model to capture these salient features and I use it to interpret the data. I find that corporate demand is the main contributor to the growth of the finance industry, but also that efficiency gains in finance have been important to limit credit rationing. Overall, the model can account for a bit more than half of the financial sector's growth.
\end{abstract}

Thomas Philippon

NYU Stern School of Business

Department of Finance

44 West 4th Street, Suite 9-190

New York, NY 10012-1126

and NBER

tphilipp@stern.nyu.edu 
In 1947, the financial sector accounted for $2.32 \%$ of U.S. GDP and $2.76 \%$ of employee compensation. In 2005, these fractions were $7.69 \%$ and $7.65 \%$, respectively. Why is there an upward trend in the size of the financial sector? Why is the U.S. devoting a growing share of its human capital to the provision of financial services? What are the economic forces than pin down the equilibrium size of the financial sector? I attempt to answer these questions using theory and evidence.

Understanding the evolution of the financial sector is important for several reasons. First, finance, unlike the rest of the service sector, would not exist in an Arrow-Debreu economy. If markets were complete, the finance industry would be trivial. How then should we interpret the dramatic growth of this industry over the past 60 years? Does this imply that the U.S. economy has drifted away from the Arrow-Debreu benchmark? Is information becoming more asymmetric, or enforcement more difficult? Second, the fact, documented in Goldin and Katz (2008) and Philippon and Resheff (2007), that finance attracts a growing share of the economy's human capital prompts the question of the efficiency of this allocation. An analysis of the equilibrium size of finance is needed before we can hope to answer this question. Finally, an explanation of the financial sector's growth requires a specific model, because the mechanisms emphasized in the literature on structural change are not relevant for many financial services, especially the ones offered to corporations. ${ }^{1}$

Before studying the role of corporate finance, I start by considering some alternate explanations, and find that they are not satisfactory. While financial globalization might seem like a plausible explanation, it does not account for the increasing size of finance. The U.S., unlike the U.K., is not a large exporter of financial services, and financial globalization is a relatively recent phenomenon, whereas the growth of finance has been continuous over the post-war period. Moreover, the growth of the financial sector does not simply correspond to a growing number of traders. In fact, credit intermediation is still the largest contributor to financial value added. Finally, explanations based on different trends in total factor productivity (TFP) are not very promising, because labor-saving technological progress has often contributed negatively to the size of the financial sector. ${ }^{2}$ In addition, the value added

\footnotetext{
${ }^{1}$ See Baumol (1967). Financial services, unlike health care for instance, do not enter preferences directly. Similarly, on the corporate side, they do not affect production directly. Financial services only facilitate production or consumption.

${ }^{2}$ Philippon and Resheff (2007), for instance, document a steep decline in the number of bank clerks.
} 
of many financial services depends directly on the productivity of industrial firms, so that, in theory, technological progress in the industrial sector leads to balanced growth with a constant relative size for the finance industry. This is indeed the case in the model presented below. What other factors could explain the increasing size of financial sector?

I argue that corporate finance is an important factor in the evolution of the financial sector. I present new evidence on the evolution of the cross-sectional distribution of cash flows and investment expenditures. I find that firms with low cash flows account for a growing share of total investment. In the 1950s, most corporate investment was done by firms with high cash flows. In 2000, half of total investment was done by firms whose cash flows covered less than a third of their capital expenditures. This evolution is consistent with an increasing demand for financial intermediation. It might also, however, be a consequence of improvements in financial intermediation, i.e., a supply shift. In addition, one would like to understand how these evolutions relate to the amount of outstanding corporate liabilities, to credit rationing, and to aggregate investment itself. A good understanding of these issues requires an equilibrium model.

A simple model of a production economy with financing constraints, endogenous monitoring and career choices is therefore developed to interpret the evidence. The model economy is populated by overlapping generations of agents who choose to work in the financial or in the non-financial sector. Agents in the non-financial sector have different productivities and receive different investment opportunities. Moral hazard limits borrowing, and agents with good opportunities but low current cash flows cannot always invest. Agents in the financial sector improve enforcement and relax borrowing constraints. In equilibrium, agents must be indifferent between careers in the financial and non-financial sectors, and the market for corporate financial services must clear.

Theoretically, the joint distribution of productivity and investment opportunities is a fundamental determinant of the aggregate demand for financial services. The intuition is that, when firms with investment opportunities also receive high cash flows, there is little demand for intermediation, even if moral hazard is severe. On the other hand, efficiency gains in finance have ambiguous consequences for the size of the financial sector. When the financial sector is inefficient, efficiency gains increase its size, but when it is already quite efficient, further gains reduce its size. 
I propose a quantitative interpretation of the growth of the U.S. financial sector since the 1950s. Using only data from the non financial sector, I use the model to predict the evolution of the financial sector. The model uses information from the aggregate investment to GDP ratio, and the joint distribution of cash flows and investments, in order to recover the deep parameters of the economy, and to generate quantitative predictions. The model correctly predicts the evolution of outstanding credit market instruments, and accounts for one half to two third of the increase in the GDP share of the financial sector. When I break down the evolution of supply and demand, I find that demand for corporate financial services is the main contributor to the increase in size, and that efficiency gains in finance were crucial to limit credit rationing.

The main contributions of the paper are to present new evidence, to provide a model to interpret this evidence, and to analyze the evolution of the U.S. financial sector. The evidence includes the share of investment by low cash firms, the distinction between value added and assets under management, and the functional analysis (advocated by Merton (1995)) of the tasks performed in the finance industry. To the best of my knowledge, this paper is the first to propose an interpretation of the growth of the financial sector over the post-war period.

The paper is related to the literature on financial intermediation, reviewed in Gorton and Winton (2003). Following Diamond (1984) and Holmström and Tirole (1997), among others, I focus on corporate finance and monitoring in the presence of moral hazard. My choice is motivated by the evidence discussed in Section 1, and by the argument of Freixas and Rochet (1997) that "the progress experienced recently in telecommunications and computers implies that FIs would be bound to disappear if another, more fundamental, form of transaction costs were not present."

By trying to estimate quantitatively the importance of corporate finance frictions, this paper is related to the work of Biais, Bisière, and Décamps (2000) and Hennessy and Whited (2007). Using firm level data and theoretical models, they provide structural estimates of the severity of moral hazard, and of the costs of external finance. This paper estimates the macroeconomic equivalent of these costs. The macro and micro estimates are compared in Section 4. In general equilibrium, however, the price of external finance is endogenous, because it is always possible, though not always optimal, to increase the number of agents 
working in the financial sector.

The paper is also related to the literature on financial development: Greenwood and Jovanovic (1990), Bencivenga and Smith (1991), King and Levine (1993), Do and Levchenko (2007) and Greenwood, Sanchez, and Wang (2007) among others. Do and Levchenko (2007), in particular, find that financial development responds to the demand for external finance generated by international trade. In this paper, I estimate how the financial sector responds to the demand for external finance generated by changes in the joint distribution of cash flows and investment opportunities.

The remaining of the paper is organized as follows. Section 1 presents the evidence and discusses alternate explanations. Section 2 presents the model and Section 3 characterizes the equilibrium allocations. Section 4 presents the quantitative results. Section 5 concludes.

\section{Evidence}

This section characterizes the evolution of the U.S. financial sector. It shows why it is important to distinguish assets under management from value added, and it presents the evidence on the cross-sectional distribution of cash flows and capital expenditures.

\section{Value added and compensation shares}

Figure 1 displays the share of GDP and the share of employee compensation accounted for by the Finance and Insurance industry over the post-war period. The shares are similar and have grown together, almost linearly. ${ }^{3}$ Figure 2 shows the evolution of the shares of various subsectors (starting in 1977 because of data limitations). The data is from the National Income and Product Accounts (NIPA). In NIPA, the finance industry is split into 4 categories: (i) Credit intermediation; (ii) Investment banking, venture capital, brokerage, and portfolio management; (iii) Insurance and reinsurance; (iv) Pension funds, mutual funds (open- and closed-end), and trusts. Figure 2 shows that credit intermediation is the dominant activity, and, together with investment banking and brokerage, the fastest growing. Funds and trusts account for a negligible share of value added. This brings up two important issues: the distinction between assets and value added, and the classification of the various activities in a theoretical model.

\footnotetext{
${ }^{3}$ See Philippon and Resheff (2007) for a detailled empirical analysis of employment and wages in the financial sector.
} 


\section{Value added versus assets under management}

Figure 3 shows the allocations of value added and assets within the financial sector in 2005 . The data on value added is from the NIPA, as described above. The data on assets is from the Flow of Funds Accounts. To create Figure 3, I have mapped the Flow of Funds into the NIPA classification. Figure 3 makes it clear that there is no simple relationship between value added and assets under management. As a result, the common wisdom that the rise of the pension and mutual funds industry is the main factor behind the evolution of finance severely misses the point. In fact, from a theoretical perspective, funds and trusts resemble the Arrow-Debreu benchmark: they control a lot of assets without using much economic resources. I conclude that, to understand the growth of the financial sector, one should not focus on mutual funds, but rather on credit intermediaries, investment banks and private equity.

\section{Functional analysis}

From a theoretical perspective, industry classifications are useful only to the extent that they can be mapped into economic functions, as advocated by Merton (1995). To do so, one must look at the tasks performed by employees of the financial sector. Figure 4 presents estimates of the share of finance activity that is presumably related to corporate finance and credit intermediation. The data is from Philippon and Resheff (2007) and the primary source is the Current Population Survey. The estimates are based on the compensation of employees, i.e., on employment weighted by relative wages. ${ }^{4}$ The baseline share is constructed by removing the jobs that are not related to corporate finance or to credit intermediation. The excluded categories are: insurance specialists; traders of stocks, bonds, commodities and other assets; personal financial advisors; janitors, private security and miscellaneous employees. The baseline share is one minus the compensation share of the excluded categories. Figure 4 shows that the baseline share is relatively stable, around $75 \%$. This measure might overestimate corporate finance services, however, because it includes all clerical and administrative jobs. Some of these workers keep track of loans to businesses, but some also provide services to households. I therefore compute a second estimate that excludes all clerks and administrative workers. This adjusted share increases over time

\footnotetext{
${ }^{4}$ Weighting is important because wages vary with occupations. For instance, traders earn more than clerks.
} 
because of the decrease in clerical employment. Based on Figure 4, I will assume that approximately $60 \%$ of finance activity is related to corporate finance, and that this share has not declined over time.

\section{Globalization}

Globalization does not account for the growth of the U.S. financial sector, for two reasons. First, the U.S., unlike the U.K., is not a large exporter of financial services. According to IMF statistics, in 2004 , the U.K. financial services trade balance was $+\$ 37.4$ billions while the U.S. balance was $-\$ 2.3$ billions: the U.S. was actually a net importer. In 2005, the U.K. balance was $+\$ 34.9$ billions, and the U.S. balance was $+\$ 1.1$ billions. Second, financial globalization is a relatively recent phenomenon (see Obstfeld and Taylor (2002), and Bekaert, Harvey, and Lumsdaine (2002)), while Figure 1 shows that the growth of the financial sector has been continuous since the end of World War II.

\section{Investment share of low cash firms}

The evidence just discussed suggests that neither the development of mutual and pension funds, nor globalization, are enough to account for the growth of the financial sector. In addition, Figures 2 and 4 highlight the role of credit intermediation and corporate finance. What is needed now is to look at the non financial sector in order to understand how financial services are used. Corporate finance is fundamentally related to investment and internal funds. Firms with low cash flows and high capital expenditures must raise external finance, and they require financial services to do so. Empirically, I compute the share of investment done by firms whose cash flows are less than one third of their capital expenditures:

$$
s_{t}=\frac{\sum_{i} \text { capex }_{i t} *\left(\text { income }_{i t}<0.33 * \text { capex }_{i t}\right)}{\sum_{i} \text { capex }_{i t}} .
$$

I use all firms in the industrial Compustat files with non missing values for income and capital expenditures, excluding finance, insurance and real estate. In equation (1), $i$ is the firm identifier, income is income before extraordinary items (Data \#18), and capex is capital expenditures (Data \#128). To avoid issues with the timing of income and investment - because of time-to-build or accounting rules - capex $x_{i t}$ and income $_{i t}$ are the sum of capital expenditures and income in year $t-2, t-1$ and $t$. Figure 5 displays the shares of investment 
accounted for by low cash firms, defined using three different cutoff values: $0.33,0.25$ and 0.15. All three measures show strong upward trends. ${ }^{5}$

The evidence in Figure 5 is consistent with increasing demand for corporate finance services, but it might also reflect improvements in financial intermediation, i.e., a supply shift. Evaluating the respective contributions of supply and demand is important to understand the evolution of the economy. For instance, demand and supply shocks in the market for corporate finance are likely to have opposite implications for equilibrium credit rationing and aggregate investment. A model is needed to understand the contributions of supply and demand, and their connections to other characteristics of the economy, such as the amount of outstanding corporate liabilities, and aggregate investment itself. The next section presents a simple equilibrium model of corporate finance that can help us interpret the evidence.

\section{A simple equilibrium model}

Consider an infinite horizon production economy with overlapping generations of agents who live for two periods. The economy has two sectors, industrial and financial. The industrial sector produces a good that can be consumed and invested. The financial sector produces monitoring services that are used by entrepreneurs of the industrial sector. In the description of the model, upper case letters denote variables that follow an upward trend because of technological progress in the industrial sector (measured by $X_{t}$ ). In Section 3 , I use lower case letters for the detrended variables.

\subsection{Technology and preferences}

Agents discount the future at rate $\rho$ and the size of each generation is normalized to 1 . An agent $i \in[0,1]$ born at time $t$ consumes $C_{1, t}^{i}$ when she is young and $C_{2, t+1}^{i}$ when she is old. The agent chooses a career and a consumption path in order to maximize her expected utility:

$$
U_{t}^{i}=E_{t}\left[C_{1, t}^{i}+\frac{C_{2, t+1}^{i}}{1+\rho}\right] .
$$

\footnotetext{
${ }^{5}$ One might worry about a change in the coverage of Compustat. However, after 1975, the ratio of the number of employees covered by Compustat to total non-farm payrolls is constant.
} 


\section{Career Choice}

In their first period, agents choose a career. Let $n_{t}$ be the mass of agents who choose the industrial sector. The remaining $1-n_{t}$ enter the financial sector. I start by describing an agent's career within the industrial sector. Let $X_{t}$ be a measure of the aggregate productivity of the industrial sector at time $t$. After she enters the industrial sector, an agent receives two shocks: $\alpha \in(0, \infty)$ and $\tilde{\theta} \in\{0, \theta\}$. Both shocks are publicly observable. The first shock, $\alpha$, determines the relative productivity of the agent in the first period of her life. An agent $i \in\left[0, n_{t}\right]$ who receives a shock $\alpha^{i}$ produces $\alpha^{i} X_{t}$ units of output. Let $\bar{\alpha}$ be the unconditional mean of $\alpha$ :

$$
\bar{\alpha} \equiv E[\alpha]
$$

The second shock, $\tilde{\theta}$, measures the investment opportunity of the agent. Investment requires $X_{t}$ units of output at time $t$ and delivers $\tilde{\theta} X_{t}$ units of capital at time $t+1$. Each unit of capital is a Lucas tree: it delivers one unit of consumption good per period and depreciates at rate $\delta$. Let $\pi$ be the probability of receiving an investment opportunity:

$$
\pi \equiv \operatorname{Pr}(\tilde{\theta}=\theta)
$$

The shocks $\alpha$ and $\tilde{\theta}$ are correlated. Let $F^{\theta}$ (.) be the cumulative distribution function of $\alpha$ conditional on $\tilde{\theta}=\theta$, and let $f^{\theta}($.$) be the corresponding density function. The distribution$ of $\alpha$ conditional on $\tilde{\theta}=0$ does not need to be specified explicitly.

\section{Production and capital accumulation}

Let $K_{t}$ be the stock of capital (Lucas trees) at time $t$. Using equation (3), industrial output is:

$$
Y_{t}=\bar{\alpha} n_{t} X_{t}+K_{t}
$$

This functional form is discussed later, with the other assumptions of the model. Capital accumulates over time according to:

$$
K_{t+1}=(1-\delta) K_{t}+\theta e_{t} X_{t}
$$

where $e_{t}$ is the number of entrepreneurs. Given the definition of $\pi$ in equation (4), we must have:

$$
e_{t} \in\left[0, \pi n_{t}\right]
$$




\section{Stealing and monitoring}

After investing $X_{t}$ unit at time $t$, an entrepreneur can steal $z X_{t}$ units of capital at time $t+1$, while the remaining $\theta X_{t}-z X_{t}$ is lost. The parameter $z \in[0, \theta)$ captures the severity of the moral hazard problem. Monitoring can be used to limit stealing. If $m_{t}^{i}$ units of monitoring are allocated to entrepreneur $i \in\left[0, e_{t}\right]$, she can steal only $\left(z-m_{t}^{i}\right) X_{t}$. Each agent in the industrial sector produces $\mu$ units of monitoring.

\subsection{Markets}

\section{Market clearing}

Let $C_{1, t}$ be the total consumption of the young agents, and let $C_{2, t}$ be the total consumption of the old agents. Note that $C_{1, t}$ and $C_{2, t}$ are aggregate quantities and that agents within a generation typically have different levels of consumption. Equilibrium in the goods market requires:

$$
C_{1, t}+C_{2, t}+e_{t} X_{t}=K_{t}+\bar{\alpha} n_{t} X_{t}
$$

Equilibrium in financial intermediation requires:

$$
\int_{i \in\left[0, e_{t}\right]} m_{t}^{i} d i=\mu\left(1-n_{t}\right) .
$$

The left hand side of equation (9) is the demand for monitoring services coming from all the

entrepreneurs active at time $t$. The right hand side is the aggregate supply of monitoring by the $1-n_{t}$ agents who work in the financial sector.

\section{Asset prices}

Let $r_{t}$ be the interest rate between period $t$ and $t+1$. The ex-dividend price of one unit of installed capital satisfies the dynamic equation:

$$
q_{t}=\frac{1+(1-\delta) q_{t+1}}{1+r_{t}}
$$

The net present value of a project is $v_{t} X_{t}$, where:

$$
v_{t}=\theta q_{t}-1
$$

\subsection{Discussion of the model}

Levine (2005) defines five broad functions for the financial sector: screening, monitoring, trading, pooling of savings, and easing the exchange of goods and services. I abstract from 
transaction costs, liquidity provision, and trading frictions. For the purposes of this paper, the distinction between screening and monitoring is inconsequential. ${ }^{6}$ One should think of the model as including the screening, certification, monitoring and governance functions of the financial sector.

Modeling financial intermediaries as monitors follows a long tradition in economics and finance, and much work has been done on the issue of who monitors the monitors (Diamond (1984), Holmström and Tirole (1997)). I abstract from this issue by not introducing asymmetric information or moral hazard between savers and financial intermediaries. Allocations within the financial sector are therefore irrelevant; only productivity $\mu$ matters.

Regarding preferences, the main assumption is that agents are risk neutral. The paper does not take into account the services provided to households, in terms of liquidity and personal insurance. Risk neutrality also implies that the real rate of interest is equal to $\rho$ as long as consumption is interior for some agents.

The important assumptions for the production function in equation (5) are constant returns to scale and labor augmenting technology. It is well known that these are needed for balanced growth. The fact that $K$ and $n$ are perfect substitutes is only a simplification to reduce the dimension of the system and allow a simple analysis of heterogeneity among entrepreneurs. Similarly, the assumption of exogenous technological progress is convenient for the positive analysis presented here, but is not critical. It is conceptually straightforward to relax these assumptions: Philippon (2007), for instance, presents a normative analysis in an endogenous growth model with a standard Cobb-Douglas production technology.

Finally, the model assumes a closed economy. This means that the entire demand for financial services comes from domestic firms. Section 1 explains why this is a natural benchmark, and Section 4 reconsiders the issue in light of the quantitative results.

\section{Financial services in equilibrium}

The definition of an equilibrium is standard. Agents maximize (2) by choosing a career and a consumption path. Potential entrepreneurs choose whether to invest or not, and all markets clear.

\footnotetext{
${ }^{6} \mathrm{~A}$ model where the financial sector selects and certifies projects has similar equilibrium implications as the model presented here.
} 


\subsection{Balanced growth}

Aggregate productivity $X_{t}$ grows at rate $\gamma: X_{t+1}=(1+\gamma) X_{t}$. I use lower-case letters to denote the quantities scaled by productivity: $k_{t} \equiv K_{t} / X_{t}, c_{t} \equiv C_{t} / X_{t}$, and so on. The scaled quantities are constant on the balanced growth path. The interest rate is also constant. Equation (6) implies $k=\theta e /(\gamma+\delta)$, and equation (10) implies $q=1 /(r+\delta)$. Equation (11) become:

$$
v=\frac{\theta}{r+\delta}-1
$$

Combining the market clearing condition (8) with the budget constraint of old agents $c_{2}=$ $k+(1-\delta) q k$, we obtain the investment/saving equation:

$$
c_{1}=\bar{\alpha} n-\varphi(r) e,
$$

where the function $\varphi(r)$ is defined by:

$$
\varphi(r) \equiv 1+\frac{1-\delta}{r+\delta} \frac{\theta}{\gamma+\delta}
$$

I now describe the balanced growth of three economies. I quickly discuss the economy without moral hazard, and the economy with moral hazard but without intermediation. The model is simple enough that these cases can be understood directly by looking at Figures 6 and 7. I then characterize the equilibrium with moral hazard and intermediation, which is the main focus on the paper.

\subsubsection{No moral hazard}

Consider first the case where $z=0$. Projects are funded if and only $v=\theta /(r+\delta)-1$ is positive. There are no financiers, and $n=1$. The demand for entrepreneurship is:

$$
e^{d}(r):\left\{\begin{array}{c}
=\pi \text { if } r+\delta<\theta \\
\in[0, \pi] \text { if } r+\delta=\theta \\
=0 \text { if } r+\delta>\theta
\end{array}\right\}
$$

From equation (12) and the constraint that $c_{1}$ be positive, we get:

$$
e^{s}(r):\left\{\begin{array}{c}
=0 \quad \text { if } r<\rho \\
\in[0, \bar{\alpha} / \varphi(\rho)] \quad \text { if } r=\rho \\
=\bar{\alpha} / \varphi(r) \quad \text { if } r>\rho
\end{array}\right\}
$$

The equilibrium condition $e^{s}(r)=e^{d}(r)$ pins down the interest rate. The following proposition characterizes the equilibrium, which is also depicted on Figure 6: 
Proposition 1 Without moral hazard, entrepreneurship and investment take place if and only if $\theta>\rho+\delta$. All projects are financed when $(1+\gamma) \pi \leq(\delta+\gamma) \bar{\alpha}$. Otherwise $r=\theta-\delta$, and $e<\pi$.

One important feature of this economy is that the equilibrium is independent of the conditional distribution of productivity $F^{\theta}($.$) . Only the unconditional mean \bar{\alpha}$ matters. From now on, I assume that the no-moral hazard economy has a strictly positive investment rate with an interior solution for consumption:

Assumption 1: $\theta>\rho+\delta$ and $\bar{\alpha}>\pi \varphi(\rho)$.

\subsubsection{Moral hazard without intermediation}

Consider now the case where $z>0$, but $\mu=0$. An entrepreneur borrows $b$ when she is young and produces $\theta$ units of capital when she is old. ${ }^{7}$ The cum-dividend value of one unit of capital is $(1+r) /(r+\delta)$. If the entrepreneur defaults, she gets $z(1+r) /(r+\delta)$. If she does not default, she gets $(1+r) \theta /(r+\delta)-b(1+r)$. The maximum amount of borrowing allowed is therefore $b^{\max }=(\theta-z) /(r+\delta)$. An entrepreneur with current income $\alpha$ can finance her investment if and only if $\alpha+b^{\max }>1$. This defines a threshold $\alpha_{h}$ for financing without monitoring:

$$
1-\alpha_{h} \equiv \frac{\theta-z}{r+\delta}
$$

Internal cash must cover the difference between the pledgeable value of the project and the capital expenditures required to start the project. Entrepreneurs whose income is less that $\alpha_{h}$ are financially constrained.

Let $e^{c}(r)$ be the effective investment demand curve under moral hazard. When $r+\delta>\theta$, it collapses to zero, just like in equation (14). When $r+\delta \leq \theta$, the constrained investment demand is given by:

$$
e^{c}(r)=\pi\left(1-F^{\theta}\left(\alpha_{h}\right)\right) .
$$

When $r+\delta=\theta$, the effective demand curve is vertical and $e^{c}$ can be anywhere between 0 and $\pi\left(1-F^{\theta}\left(\frac{z}{\theta}\right)\right)$. The saving equation (15) is the same as in the economy without moral hazard. The equilibrium is depicted on Figure 7 and characterized by the following proposition:

\footnotetext{
${ }^{7}$ Recall that all these quantities are scaled by $X_{t}$.
} 
Proposition 2 Under assumption 1, and without monitoring, the interest rate is $\rho$ and the number of projects financed is $e^{c}(\rho)$.

Proof. Under assumption 1, equation (12) shows that $c_{1}>0$. Therefore $r=\rho$. Investment is pinned down by the constrained demand schedule $e^{c}$ evaluated at $r=\rho$.

\subsubsection{Active intermediation}

Consider now the case where $z>0$ and $\mu>0$. An entrepreneur with current income $\alpha$ hires $m$ units of monitoring. The pledgeable income becomes $(\theta-z+m) /(r+\delta)$. The amount of monitoring required for this entrepreneur to be able to invest is:

$$
m(\alpha)=(r+\delta)\left(\alpha_{h}-\alpha\right)
$$

Let $\phi$ be the price of one unit of monitoring. The NPV of a project, net of intermediation costs, is $v-m \phi$. It is profitable to use monitoring if $\alpha$ is more than $\alpha_{l}$, defined by:

$$
m\left(\alpha_{l}\right) \phi \equiv v
$$

Let us now turn to the supply of financial services. Agents choose their careers freely, therefore, in any equilibrium with intermediation, we must have:

$$
\mu \phi=\bar{\alpha}+\pi\left(1-F^{\theta}\left(\alpha_{h}\right)\right) v+\pi \int_{\alpha_{l}}^{\alpha_{h}}(v-\phi m(\alpha)) d F^{\theta}(\alpha)
$$

The left-hand-side of equation (20) is the value of entering the financial sector. The righthand-side is the value of entering the non-financial sector, which contains three terms: the expected income from production, the expected value of becoming an entrepreneur who can finance herself directly, and the expected value of becoming an entrepreneur who hires financial services. Combining (19) and (20), I obtain:

$$
\frac{\mu}{\pi}=\left(\frac{\bar{\alpha}}{\pi v}+1-F^{\theta}\left(\alpha_{l}\right)\right) m\left(\alpha_{l}\right)-\int_{\alpha_{l}}^{\alpha_{h}} m(\alpha) d F^{\theta}(\alpha) .
$$

Finally, equilibrium in the monitoring market requires that:

$$
\mu(1-n)=\pi n \int_{\alpha_{l}}^{\alpha_{h}} m(\alpha) d F^{\theta}(\alpha)
$$

Figure 8 describes the monitoring equilibrium. 
Proposition 3 Under assumption 1, the balanced growth path with active monitoring is characterized by $r=\rho$, and by $\alpha_{l}$ and $n$ that solve equations (21) and (22). Credit rationing persists as long as $\alpha_{l}>0$, and the size of the financial sector is strictly positive as long as $f^{\theta}\left(\alpha_{h}\right)>0$.

Proof. Under assumption 1, equation (12) shows that $c_{1}>0$. Therefore $r=\rho$. The RHS of equation (21) goes to zero as $\alpha_{l} \rightarrow \alpha_{h}$ so for any value of $\mu>0$, it is possible to find $\alpha_{l}<\alpha_{h}$ that solves equation (21). If the density $f^{\theta}\left(\alpha_{h}\right)>0$ and if $f^{\theta}$ is continuous, then the RHS of (22) is strictly positive and $n$ is strictly less than one. QED.

Some agents become financial intermediaries even when $\mu$ is very small. The price of monitoring $\phi$ can be arbitrary large, but entrepreneurs who are close enough to the cutoff $\alpha_{h}$ are always willing to buy the small amount of monitoring required to obtain financing.

\subsection{Comparative statics}

Consider first the efficiency of the financial sector. How does the size of the financial sector depend on $\mu$ ? On the one hand, an increase in $\mu$ implies that the same amount of monitoring can be performed by fewer financiers. On the other hand, the drop in the price of monitoring services leads to a surge in demand. These two forces determine the effects of changes in the productivity of monitoring services. When $n$ is close to one, the supply effect is negligible and the demand effect dominates. Therefore, starting from a value of $\mu$ close to zero, an increase in $\mu$ leads to a decrease in $n$. For a very large value of $\mu$, the density $f^{\theta}\left(\alpha_{l}\right)$ must eventually be close to zero, and $n$ must increase in response to an increase in $\mu$.

Proposition 4 The size of the financial sector goes to zero when its efficiency becomes either very small or very large. Efficiency gains in finance reduce rationing and increase investment, but have an ambiguous effect on the GDP share of the finance industry.

Proof. See appendix.

Consider now the demand for financial services. A change in $z$ affects the self-financing cutoff $\alpha_{h}$. When moral hazard worsens, credit rationing increases. The size of the financial sector might go up or down, because fewer agents invest, but the ones who do require more monitoring. 
The comparative statics for $F^{\theta}$ are unambiguous, unlike those for $z$. Remember that $F^{\theta}$ is the distribution of $\alpha$ conditional on $\tilde{\theta}=\theta$. Thus, a change in $F^{\theta}$ for a given $\bar{\alpha}$ is like changing the cross-sectional correlation between investment opportunities and current cash flows, while keeping average productivity constant. If $F^{\theta}$ moves to the left, it becomes less attractive to work in the industrial sector. The price of financial services decreases to keep agents indifferent between careers. The demand for financial services therefore increases both because of the shift in $F^{\theta}$ and because of the drop in $\alpha_{l}$.

Proposition 5 A decrease in the correlation between current income and investment options decreases $\alpha_{l}$ and increases the size of the financial sector.

Proof. See appendix.

\section{A quantitative investigation}

The quantitative investigation has two parts. I calibrate the parameters of the model by matching the characteristics of the U.S. economy at the beginning of the sample, 1956 to 1965. Then, I propose an interpretation of the evolution of the financial sector over the period 1966-2005. The key point of the exercise is that the model uses only data from the non financial corporate sector in order to predict the evolution of the financial sector. The data used in this section are presented in Table $1 .^{8}$

\subsection{Calibration}

I start by choosing standard values for the discount rate and for the depreciation rate:

\begin{tabular}{|lll|}
\hline Variable & Empirical Value & Model Parameter \\
\hline Length of 1 Period & 20 years & \\
Annual real rate & $4 \%$ & $\rho=1.04^{20}-1$ \\
Annual growth rate & $2 \%$ & $\gamma=1.02^{20}-1$ \\
Annual depreciation rate & $6 \%$ & $\delta=1-0.94^{20}$ \\
\hline
\end{tabular}

Next, I use the fact that the book value of a realized project is 1 while its market value is $\theta /(\rho+\delta)$. I obtain $\theta$ by assuming a ratio of market value to book value of $1.5 .{ }^{9}$ It

\footnotetext{
${ }^{8}$ The calibration is data intensive: it relies on long time series of aggregate and firm level measures, that are only available for the US. See Greenwood, Sanchez, and Wang (2007) for a study of a large cross-section of countries.

${ }^{9}$ Fama and French (2001) report an asset weighted average of 1.4 over the period 1963-1998.
} 
seems a priori difficult to calibrate the remaining parameters of the model, since they are not observable. Notice, however, that the equilibrium equations (21) and (22) depend only on the ratios $\mu / \pi$ and $\bar{\alpha} / \pi$. To reduce the degrees of freedom, I assume that $f^{\theta}($.$) is$ uniform over $\left[0, \alpha^{\theta}\right]$. The unknowns are therefore: $z, \mu / \pi, \bar{\alpha} / \pi$ and $\alpha^{\theta}$. I estimate the four parameters using data on four observed quantities during the first decade, 1956-1965.

\section{Capital Expenditures}

In the model economy, aggregate investment expenditures are equal to $\left(1-F^{\theta}\left(\alpha_{l}\right)\right) \pi n$, and the stock of capital along the balanced growth path is:

$$
k=\left(1-F^{\theta}\left(\alpha_{l}\right)\right) \frac{\pi n \theta}{\delta+\gamma}
$$

The gross domestic product is $\bar{\alpha} n+k$. Therefore the investment share of GDP depends only on $\alpha_{l}$ and on the ratio $\bar{\alpha} / \pi$ :

$$
\frac{1-F^{\theta}\left(\alpha_{l}\right)}{\bar{\alpha} / \pi+\left(1-F^{\theta}\left(\alpha_{l}\right)\right) \theta /(\delta+\gamma)} .
$$

I calibrate this ratio to $11 \%$ using private non-residential fixed investment divided by private value added from the National Income and Product Accounts.

\section{Investment share of low cash firms}

The parameter $\alpha$ captures the ratio of income to capital expenditures, for the firms that actually invest. I use a simple statistic to compare the model and the data: the share of total investment accounted for by firms whose income is less than one third of their capital expenditures. ${ }^{10}$ The investment share of low cash firms is based on Equation (1) in Section 1. In the model, it is:

$$
s=\left(F^{\theta}(0.33)-F^{\theta}\left(\alpha_{l}\right)\right) /\left(1-F^{\theta}\left(\alpha_{l}\right)\right) .
$$

Figure 5 displays the shares of investment accounted for by firms with $\alpha$ below $0.15,0.25$ and 0.33 .

\section{Corporate borrowing}

\footnotetext{
${ }^{10}$ This statistic is useful because it does not involve taking a ratio of income over capital expenditures. It is robust to the discrepancy between the assumptions made in the model and the fact that firm sizes are in fact very heterogenous. It also builds in the fact that large firms are more relevant than small firms
} 
In the model, firms with $\alpha<\alpha_{l}$ cannot invest, and firms with $\alpha>1$ can finance their investment entirely with their current income (see Figure 7). Total corporate borrowing in each period is therefore equal to:

$$
\pi n \int_{\alpha_{l}}^{1}(1-\alpha) d F^{\theta}(\alpha) .
$$

I compute the ratio of outstanding credit market instruments over GDP from the Flow of Funds. This ratio is shown in Table 1. The relevant variable for the calibration is the amount of new borrowing in each period. I assume that the average maturity of credit market instruments is 10 years, and I calibrate the model to a borrowing ratio equal to $1 / 10$ of the outstanding value from Table 1.

\section{Calibration}

Based on the evidence in Figure 4, I match $1-n$ as 0.6 times the value added share of the financial sector. To summarize, the calibration uses the first line of Table 1, corresponding to the period 1956-1965: investment at $11 \%$ of GDP, $n=0.979, s=0.166$, and borrowing at $3.73 \%$ of GDP. The implied parameters are:

\begin{tabular}{|llll|}
\hline$z / \theta$ & $\mu / \pi$ & $\bar{\alpha} / \pi$ & $\alpha^{\theta}$ \\
\hline 0.7558 & 3.978 & 5.151 & 1.207 \\
\hline
\end{tabular}

For robustness, I have redone the calibration assuming average maturities from 8 to 15 years for corporate bonds, and assuming that $f^{\theta}$ is downward sloping triangular instead of uniform. The quantitative properties of the model are similar.

An important parameter in the calibration is $z$. The calibration implies that moral hazard is relatively severe, and that firms are willing to pay significant fees in order to improve their access to external finance. Few empirical papers provide structural estimates of the severity of moral hazard or the costs of external finance, but two notable exceptions are Biais, Bisière, and Décamps (2000) and Hennessy and Whited (2007). Biais, Bisière, and Décamps (2000) estimate large agency costs using a sample of French firms in the 1990s. Hennessy and Whited (2007) find that the typical firm behaves as if facing external costs of equity starting at $8.3 \%$ of gross proceeds, and rising to $14.5 \%$ when proceeds reach $\$ 100$ millions. In my calibration, the average financing fees are around $10 \%$ of capital (with significant heterogeneity since some firms have access to direct finance without fees, and some other pay large fees). 


\subsection{Quantitative predictions}

Since firms that do not have enough income to cover their capital expenditures require intermediation, Figure 8 suggests an increase in the equilibrium level of financial services over time. One must keep in mind, however, that Figure 8 is based on realized capital expenditures, not on investment opportunities. Figure 8 could be explained either by a shift in $F^{\theta}$, or by a shift in the cutoff $\alpha_{l}$ for a given distribution $F^{\theta}$. A quantitative model is needed to make sense of the data.

As explained above, the model is first calibrated using values for the period 1956-1965. The point of this section is to use the model to predict the evolution of the financial sector over the next four decades, and then to compare the predictions to the actual numbers.

\section{Predictions}

I construct predicted values keeping the technological parameters $(\theta, \pi, \bar{\alpha})$ and the moral hazard parameter $z$ constant. I let the conditional distribution of income, determined by $\alpha_{t}^{\theta}$, and the relative efficiency of the financial sector, $\mu_{t}$, change over time. I use the investment to GDP ratio and the share of investment by low cash firms to pin down these two unknowns. The macroeconomic evidence is that the investment to GDP ratio is fairly constant over time, so I keep it at 11\%. The share of investment by low cash firms is presented in Table 1. I assume that the economy is on its balanced growth path in each decade and I simulate the evolution of the financial sector.

It is important to emphasize that the quantitative predictions do not use any information regarding the actual evolution of the financial sector, or regarding the credit market. I use the model to recover the values of $\alpha_{t}^{\theta}$ and $\mu_{t}$, and then to predict the GDP share of finance, and the size of the corporate credit market.

Figure 9 shows the actual and predicted size of the financial sector. In the first decade, the calibration is done so that the model accounts for exactly $60 \%$ of the actual size, as explained in the previous section. Up to the 1990s, the model seems able to predict most of the changes in the size of the financial sector. The model falls short in the more recent decade. Since the model forces all the demand for financial services to come from domestic firms, the discrepancy could reflect the globalization of the finance industry. There could also be an increase in financial services provided to U.S. households. The pure corporate 
finance model accounts for $58 \%$ of the overall increase.

Figure 10 shows the actual and predicted ratios of corporate credit market instruments to GDP. The calibration in the first period uses the actual size of the credit market, but the predictions in the next four decade do not. The model accounts well for the evolution of the credit market. It even over-predicts its development a little.

\section{Counter-factual experiments}

The quantitative predictions just described are based on the structural parameters $\alpha_{t}^{\theta}$ and $\mu_{t}$ that the model recovers from the data. From the first decade to the last one, the model estimates a drop of $\alpha_{t}^{\theta}$ from 1.2 to 0.7 , and an increase in $\mu_{t}$ from 4 to 4.6 . What is the contribution of each parameter to the overall evolution of the economy?

Table 2 shows the results of counter-factual experiments using the calibrated model. The parameters $\theta, \pi, \bar{\alpha}$ and $z$ are constant. In one experiment, $\mu$ is kept constant at 4 , and $\alpha^{\theta}$ is moved from 1.2 to 0.7 . In the other experiment, $\alpha^{\theta}$ is kept constant at 1.2 and $\mu$ is moved from 4 to 4.6. Table 2 shows that most of the increase in the size of the finance industry comes from a shift in the correlation between investment opportunities and current income. Efficiency gains in finance, however, play a key role in the evolution of investment. Without these improvements, the fraction of rationed firms would have increased substantially, and aggregate investment would have dropped. ${ }^{11}$

\section{Conclusion}

This paper is an attempt to analyze quantitatively the role of corporate finance in the growth of the U.S. financial sector over the post war period. To this end, I present new evidence, and I build an equilibrium model of corporate financial services. Using data from the non financial sector together with a calibrated version of the model, I find that a shift in the distribution of investment opportunities towards low cash firms has increased the demand for financial services over the past fifty years. This demand shift accounts for a large part of the increase in the size of the finance industry. At the same time, efficiency gains in the financial sector have limited credit rationing.

\footnotetext{
${ }^{11}$ Keep in mind that the model is non-linear, so the effects are not additive: the total change is not the sum of the two partial counter-factual changes.
} 
The paper uses a structural analysis of the allocation of resources to the financial sector in order to learn about the economy. Microeconomic studies have provided much direct evidence on the role of financial frictions. It is fair to say, however, that there is no consensus regarding the quantitative importance of these frictions for the economy as a whole. The equilibrium analysis of this paper offers a different and complementary perspective on the issue, because it is difficult to understand why an economy would spend nearly $8 \%$ of GDP on financial services if financial frictions were not important.

Many important questions remain unanswered, however. First, the model leaves almost half the financial sector's growth unexplained. One reason is clearly that the model does not take into account the services offered to households, but it remains to be shown that these services can account for the gap. Second, the model cannot address the issue of the overall efficiency of the allocation of human capital, even though it is a (necessary but not sufficient) step in that direction. 


\section{References}

Baumol, W. J. (1967): "Macroeconomics of Unbalanced Growth: The Anatomy of the Urban Crisis," American Economic Review, 57, 415-426.

Bekaert, G., C. R. Harvey, and R. Lumsdaine (2002): "Dating the Integration of World Capital Markets," Journal of Financial Economics, 65, 203-249.

Bencivenga, V. R., And B. D. Smith (1991): "Financial Intermediation and Endogenous Growth," Review of Economic Studies, 58, 195-209.

Biais, B., C. Bisière, and J.-P. Décamps (2000): "A Structural Econometric Investigation of the Agency Theory of Financial Structure," mimeo IDEI Toulouse University.

Diamond, D. W. (1984): "Financial Intermediation and Delegated Monitoring," Review of Economic Studies, 51, 393-414.

Do, Q.-T., And A. A. Levchenko (2007): "Comparative Advantage, Demand for External Finance, and Financial Development," Journal of Financial Economics, 86, 796-834.

Fama, E. F., And K. R. French (2001): "Disappearing Dividends: Changing Firm Characteristics or Lower Propensity to Pay?," Journal of Financial Economics, 60, 3-43.

Freixas, X., and J.-C. Rochet (1997): Microeconomics of Banking. MIT Press, Cambridge.

Goldin, C., And L. F. Katz (2008): "Transitions: Career and Family Lifecycles of the Educational Elite," mimeo, Harvard University.

Gorton, G., And A. Winton (2003): "Financial Intermediation," in Handbook Ot the Economics of Finance, ed. by G. M. Constantinides, M. Harris, and R. Stulz, pp. 431-552, North Holland. Elsevier.

Greenwood, J., And B. Jovanovic (1990): "Financial Development, Growth, and the Distribution of Income," Journal of Political Economy, 98, 1076-1107.

Greenwood, J., J. M. Sanchez, and C. Wang (2007): "Financing Development; The Role of Information Costs," Working Paper, University of Pennsylvania. 
Hennessy, C. A., And T. M. Whited (2007): "How Costly Is External Financing? Evidence from a Structural Estimation," Journal of Finance, 62, 1705-1745.

Holmström, B., And J. Tirole (1997): "Financial Intermediation, Loanable Funds and the Real Sector," Quarterly Journal of Economics, 112, 663-691.

King, R. G., and R. Levine (1993): "Finance and Growth: Schumpeter Might Be Right," Quarterly Journal of Economics, 108(3), 717-737.

Levine, R. (2005): "Finance and Growth: Theory and Evidence," in Handbook of Economic Growth, ed. by P. Aghion, and S. N. Durlauf, vol. 1A, pp. 865-934. Elsevier, Amsterdam.

Merton, R. C. (1995): "A Functional Perspective of Financial Intermediation," Financial Management, 24, 23-41.

Obstfeld, M., and A. M. Taylor (2002): "Globalization and Capital Markets," NBER Working Paper 8846.

Philippon, T. (2007): "Financiers versus Engineers: Should the Financial Sector Be Taxed or Subsidized?," Working Paper, NYU.

Philippon, T., And A. Resheff (2007): "Skill Biased Financial Development: Education, Wages and Occupations in the U.S. Financial Sector," Working Paper, New York University. 


\section{A Appendix}

\section{Comparative statics}

Let $\Delta[$.$] denote the total difference of a function or a variable of interest. To prove the$ various propositions, I differentiate equation (21):

$$
\Delta\left[\frac{\mu}{\pi}\right]=\left(\Delta\left[\frac{\bar{\alpha}}{\pi v}\right]-\Delta\left[F^{\theta}\right]\left(\alpha_{l}\right)\right) m\left(\alpha_{l}\right)+\left(\frac{\bar{\alpha}}{\pi v}+1-F^{\theta}\left(\alpha_{l}\right)\right) \Delta\left[m_{l}\right]-\int_{\alpha_{l}}^{\alpha_{h}} \Delta\left[m d F^{\theta}\right]
$$

and equation (22):

$$
\left(\int_{\alpha_{l}}^{\alpha_{h}} m d F^{\theta}+\frac{\mu}{\pi}\right) \frac{\Delta[n]}{n}=\frac{1-n}{n} \Delta\left[\frac{\mu}{\pi}\right]-\int_{\alpha_{l}}^{\alpha_{h}} \Delta\left[m d F^{\theta}\right]+m\left(\alpha_{l}\right) f^{\theta}\left(\alpha_{l}\right) \Delta\left[\alpha_{l}\right] .
$$

These formula hold because the boundary terms with $\alpha_{l}$ cancel out and because $m\left(\alpha_{h}\right)=0$. The monitoring function from equation (18) can be written as:

$$
m(\alpha)=z-\theta+(\rho+\delta)(1-\alpha) .
$$

The total difference of this equation is:

$$
\Delta[m]=\Delta[z]-\Delta[\theta]-(\rho+\delta) \Delta[\alpha]+\Delta[\rho+\delta](1-\alpha) .
$$

\section{Proof of proposition 4}

Consider first the limit when $\mu \rightarrow 0$. First, rewrite (20) as

$$
\frac{\mu}{\pi m\left(\alpha_{l}\right)}=\frac{\bar{\alpha}}{\pi v}+1-F^{\theta}\left(\alpha_{l}\right)+\int_{\alpha_{l}}^{\alpha_{h}}\left(1-\frac{m(\alpha)}{m\left(\alpha_{l}\right)}\right) d F^{\theta}(\alpha) .
$$

As $\mu$ goes to zero, $m\left(\alpha_{l}\right)$ also goes to zero and $\alpha_{l} \rightarrow \alpha_{h}$. We need to evaluate the limit of the integral. For all $\alpha \in\left[\alpha_{l}, \alpha_{h}\right]$, we know that $0<m(\alpha)<m\left(\alpha_{l}\right)$ and therefore:

$$
\left\|\int_{\alpha_{l}}^{\alpha_{h}}\left(1-\frac{m(\alpha)}{m\left(\alpha_{l}\right)}\right) d F^{\theta}(\alpha)\right\| \leq F^{\theta}\left(\alpha_{h}\right)-F^{\theta}\left(\alpha_{l}\right) .
$$

We can see that the integral goes to zero as $\mu$ goes to zero and:

$$
\lim _{\mu \rightarrow 0} \frac{\mu}{\pi m\left(\alpha_{l}\right)}=\frac{\bar{\alpha}}{\pi v}+1-F^{\theta}\left(\alpha_{h}\right) .
$$

Using equation (22), we see that $(1-n) / n=\pi / \mu \int_{\alpha_{l}}^{\alpha_{h}} m d F^{\theta}$. Since the monitoring function $m$ is decreasing in $\bar{\alpha}$, it follows that

$$
\left\|\int_{\alpha_{l}}^{\alpha_{h}} m(\alpha) d F^{\theta}(\alpha)\right\| \leq m\left(\alpha_{l}\right)\left(F^{\theta}\left(\alpha_{h}\right)-F^{\theta}\left(\alpha_{l}\right)\right)
$$

Since we have shown that $\mu / m\left(\alpha_{l}\right)$ has a finite limit, it follows that $1-n \rightarrow 0$. In the other limit when $\mu \rightarrow \infty$, the result is clear from equation (22) since the integral of the right-hand-side is bounded by $\int_{0}^{\alpha_{h}} m(\alpha) d F^{\theta}(\alpha)$.

Consider the impact of a change in $\mu$. From equation (21), we see that

$$
\Delta\left[\frac{\mu}{\pi}\right]=-(\rho+\delta)\left(\frac{\bar{\alpha}}{\pi v}+1-F^{\theta}\left(\alpha_{l}\right)\right) \Delta\left[\alpha_{l}\right]
$$


So it is clear that $\alpha_{h}$ decreases with $\mu$. The effect on the size of the finance industry, however, is ambiguous. From the monitoring market clearing (22), we see that

$$
\left(\int_{\alpha_{l}}^{\alpha_{h}} m d F^{\theta}+\frac{\mu}{\pi}\right) \frac{\Delta[n]}{n}=\frac{1-n}{n} \Delta\left[\frac{\mu}{\pi}\right]+m\left(\alpha_{l}\right) f^{\theta}\left(\alpha_{l}\right) \Delta\left[\alpha_{l}\right]
$$

The sign of the RHS clearly depends on the value of $n$. QED.

Proof of proposition 5

For a change in $z$, we get

$$
(\rho+\delta)\left(\frac{\bar{\alpha}}{\pi v}+1-F^{\theta}\left(\alpha_{l}\right)\right) \Delta\left[\alpha_{l}\right]=\left(\frac{\bar{\alpha}}{\pi v}+1-F^{\theta}\left(\alpha_{h}\right)\right) \Delta[z]
$$

So an increase in $z$ increases $\alpha_{h}$. The effect on the size of the financial sector is ambiguous:

$$
\frac{\Delta[n]}{n}\left(\int_{\alpha_{l}}^{\alpha_{h}} m(\alpha) d F^{\theta}(\alpha)+\frac{\mu}{\pi}\right)=m\left(\alpha_{l}\right) f^{\theta}\left(\alpha_{l}\right) \Delta\left[\alpha_{l}\right]-\left(F^{\theta}\left(\alpha_{h}\right)-F^{\theta}\left(\alpha_{l}\right)\right) \Delta[z]
$$

On the one hand, it takes more resources to monitor a given set of firms. On the other hand, the pool of firms that are monitored shrinks. Consider now a shift in the function $f^{\theta}$. We get

$$
(\rho+\delta)\left(\frac{\bar{\alpha}}{\pi v}+1-F^{\theta}\left(\alpha_{l}\right)\right) \Delta\left[\alpha_{l}\right]=-\Delta\left[F^{\theta}\right]\left(\alpha_{l}\right) m\left(\alpha_{l}\right)-\int_{\alpha_{l}}^{\alpha_{h}} m(\alpha) \Delta\left[f^{\theta}\right](\alpha) d \varepsilon
$$

and

$$
\left(\int_{\alpha_{l}}^{\alpha_{h}} m(\alpha) d F^{\theta}(\alpha)+\frac{\mu}{\pi}\right) \frac{\Delta[n]}{n}=-\int_{\alpha_{l}}^{\alpha_{h}} m(\alpha) \Delta\left[f^{\theta}\right](\alpha) d \varepsilon+m\left(\alpha_{l}\right) f^{\theta}\left(\alpha_{l}\right) \Delta\left[\alpha_{l}\right]
$$


Table 1: Data

\begin{tabular}{cccc}
\hline Period & Finance Share of GDP & $\begin{array}{c}\text { Investment Share of } \\
\text { Firms with } \\
\text { Income<0.33*Capex }\end{array}$ & $\begin{array}{c}\text { Credit Market } \\
\text { Instruments over GDP }\end{array}$ \\
\hline $1956-1965$ & 0.035 & 0.166 & 0.373 \\
$1966-1975$ & 0.040 & 0.216 & 0.473 \\
$1976-1985$ & 0.049 & 0.275 & 0.524 \\
$1986-1995$ & 0.061 & 0.350 & 0.604 \\
$1996-2005$ & 0.075 & 0.398 & 0.624 \\
\hline
\end{tabular}

Notes: Finance Share of GDP is value added of the Finance and Insurance industry divided by GDP, both measured in current dollars. Investment share of low cash firms is the fraction of all capital expenditure in Compustat accounted for by firms whose income is less than a third of their capital expenditures. See also Figure 5. Credit Market Instruments are for the non financial corporate sector. Source: National Income and Product Accounts, Compustat, and Flow of Funds. 
Table 2: Counter- Factuals

\begin{tabular}{lcc}
\hline & $\begin{array}{c}\text { Finance Value Added over } \\
\text { GDP }\end{array}$ & $\begin{array}{c}\text { Fraction of Constrained } \\
\text { Firms }\end{array}$ \\
\hline Starting Value (from model) & 0.0210 & 0.1287 \\
Final Value (from model) & 0.0444 & 0.1287 \\
Predicted by demand shift only & 0.0382 & 0.2099 \\
Predicted by efficiency gains only & & 0.0825 \\
\hline
\end{tabular}




\section{Figure 1: The Size of the U.S. Financial Sector}

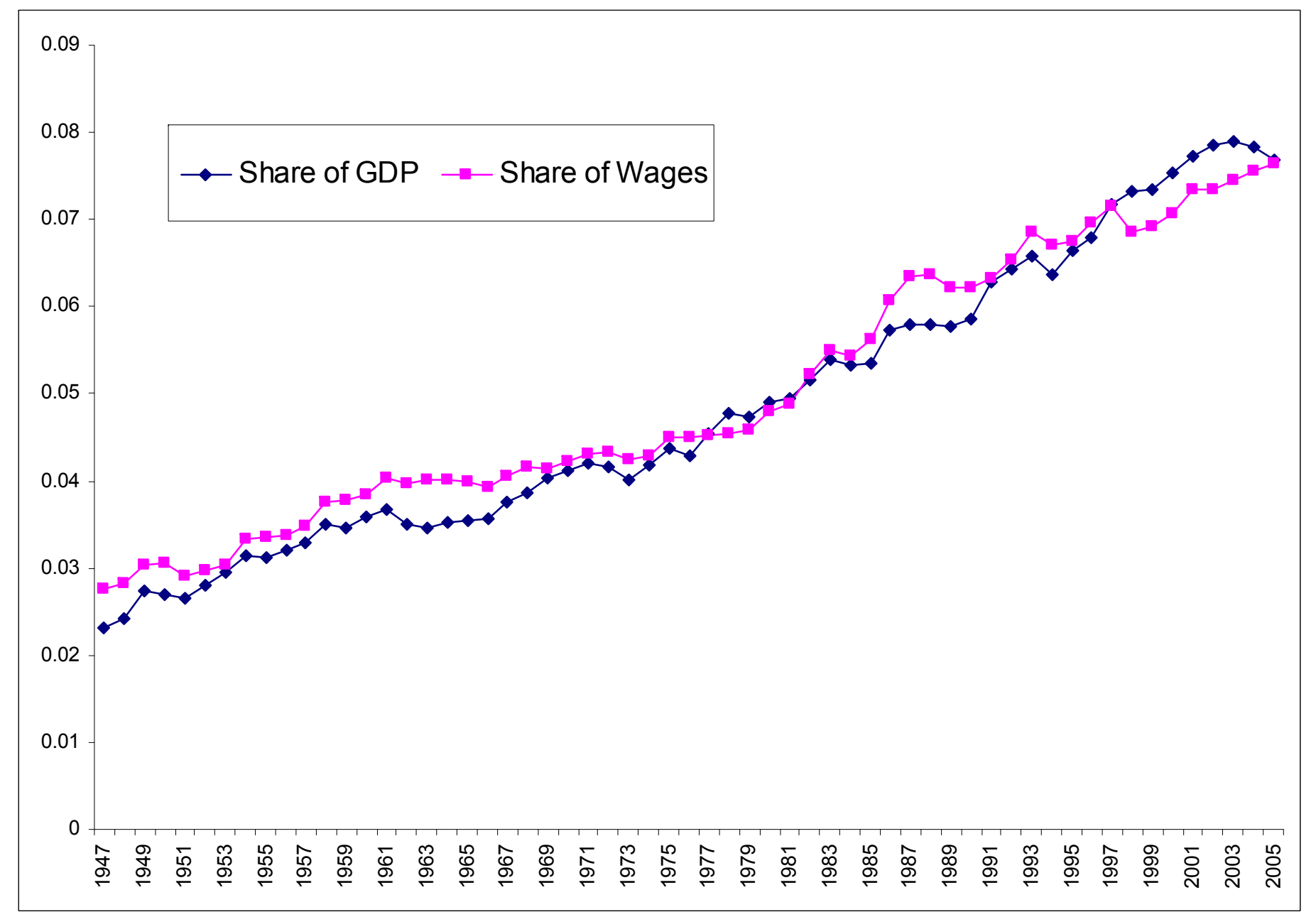

Source: U.S. National Income and Product Accounts 


\section{Figure 2: Shares of GDP}

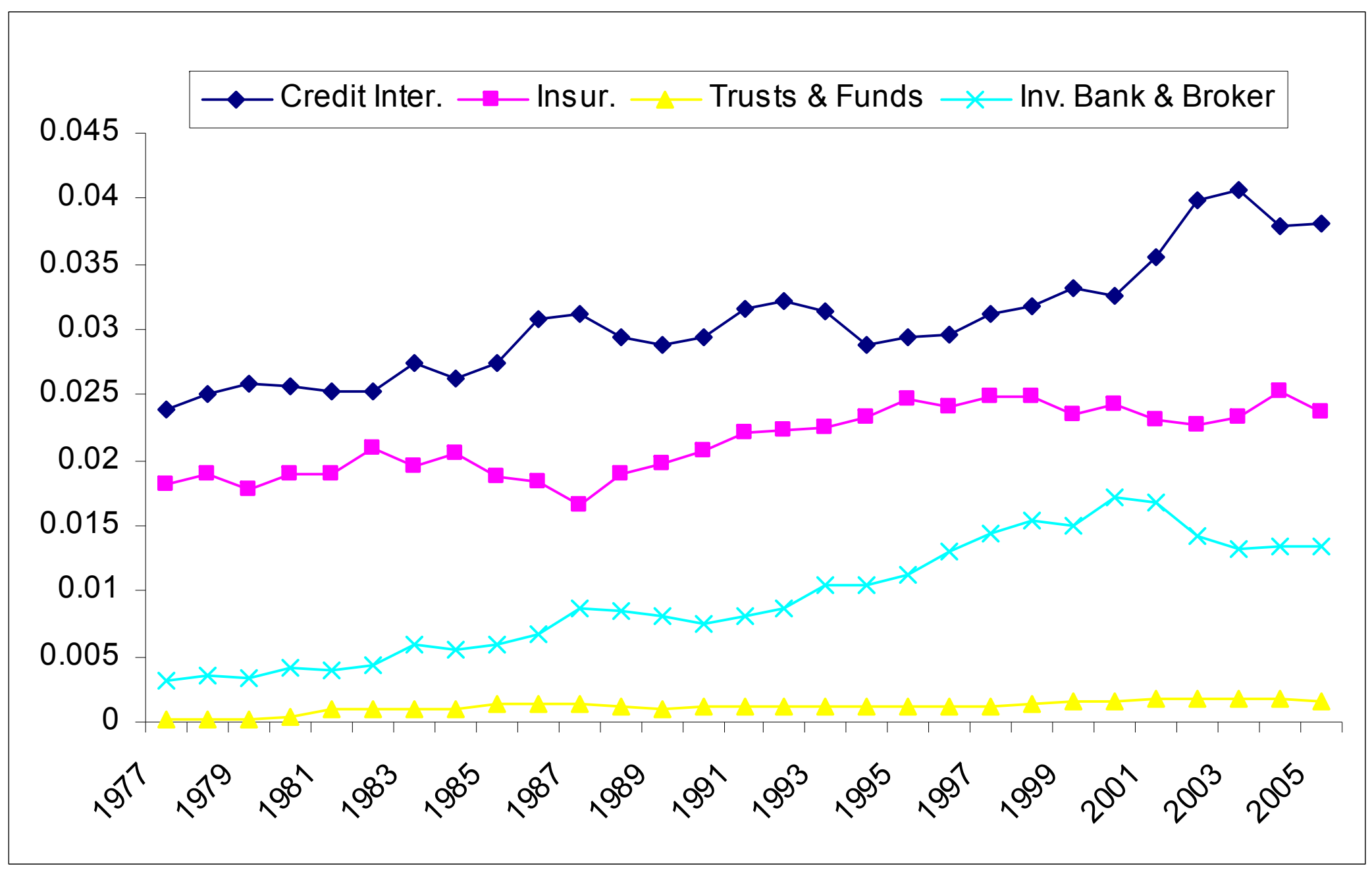

Source: U.S. National Income and Product Accounts 


\section{Figure 3: Allocations within the Financial Sector (2005)}

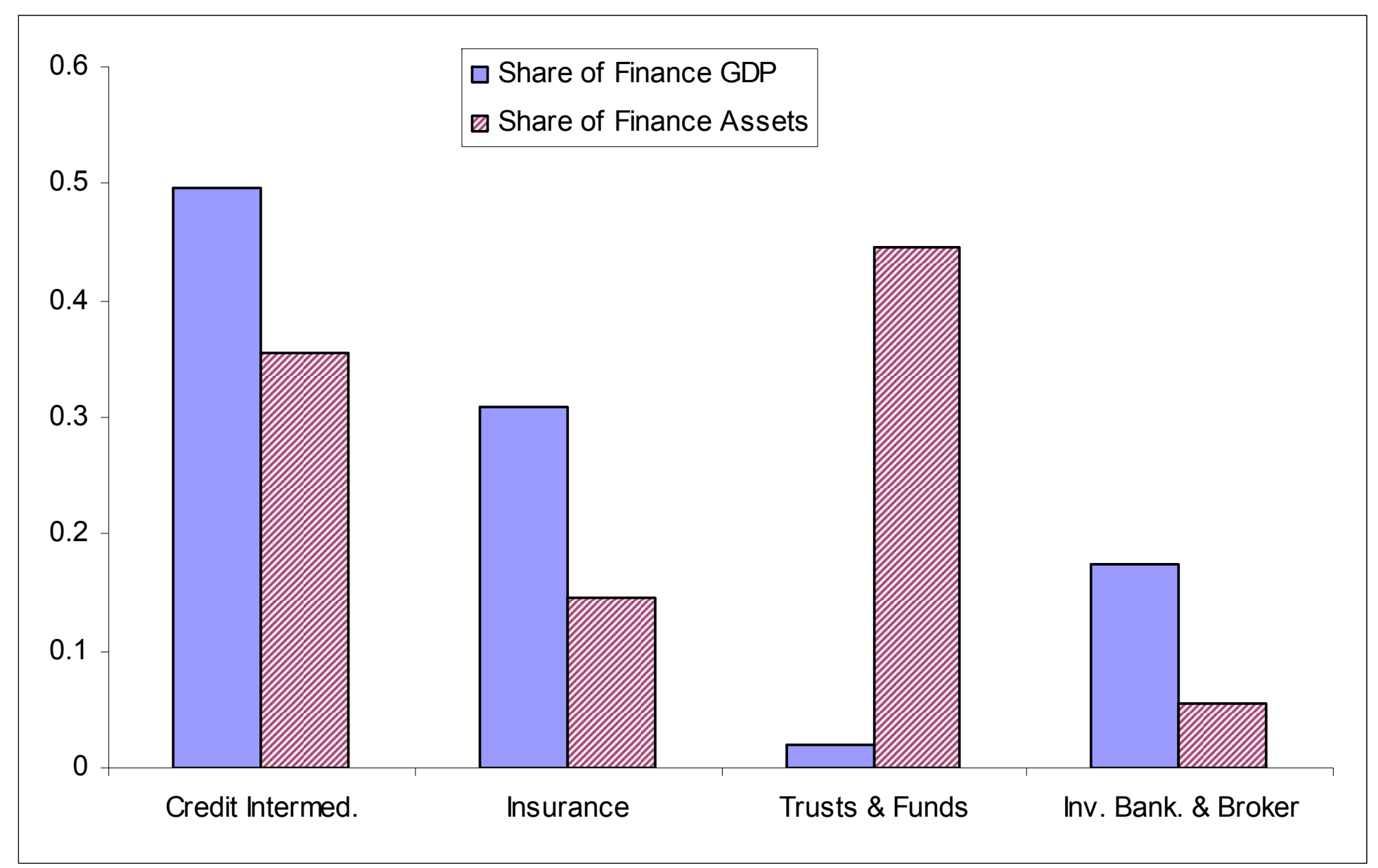

Reading: The insurance industry accounts for $14.6 \%$ of the assets of the financial sector, and for $30.9 \%$ of its value added, in 2005. Source: U.S. National Income and Product Accounts, and Flow of Funds. 


\section{Figure 4: Estimates of the Share of Finance Activity related to Corporate Finance.}

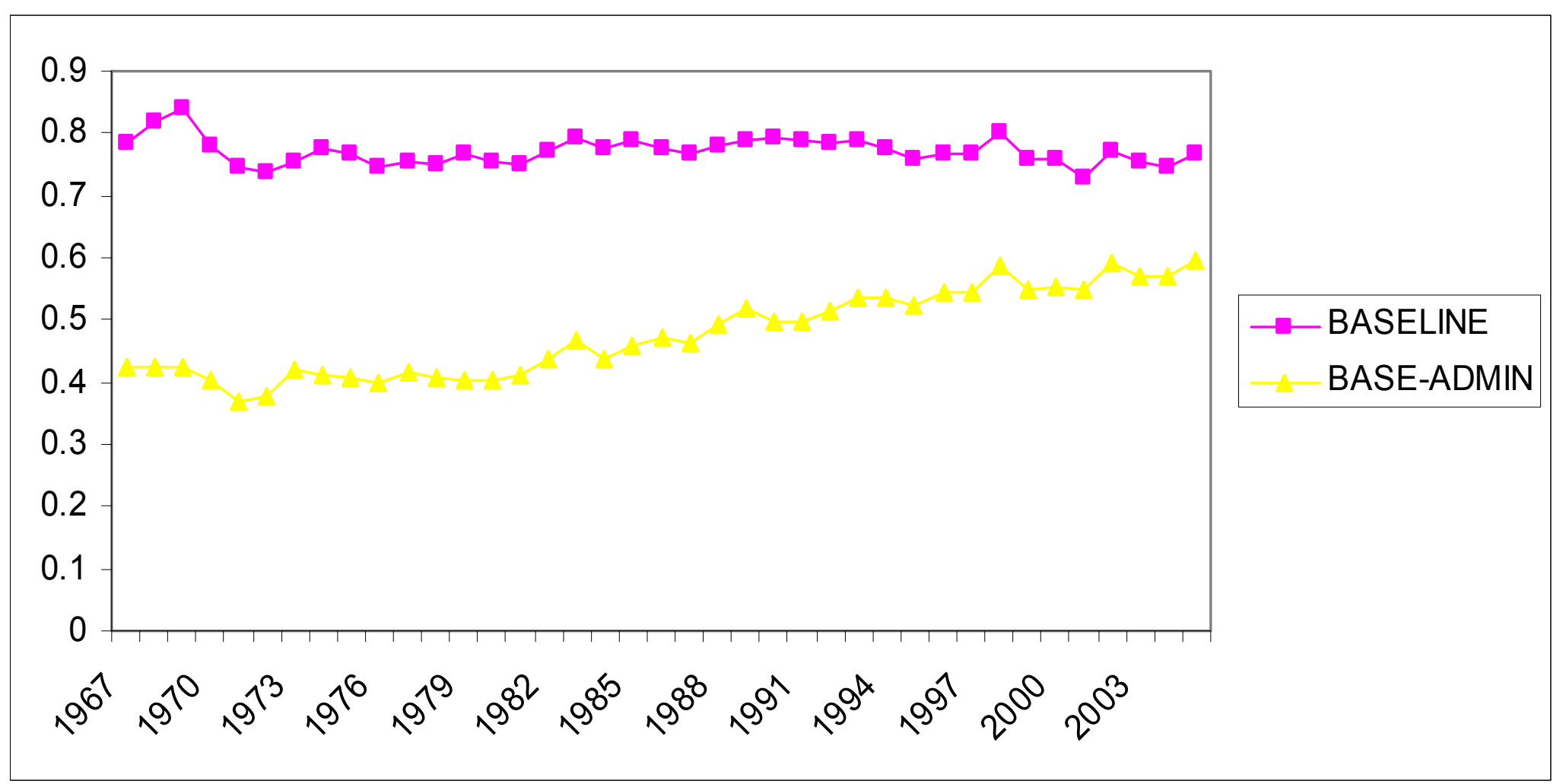

Notes: The baseline share is computed as one minus the compensation share of insurance specialists; traders of stocks, bonds, commodities and other assets; personal financial advisors; janitors, private security and miscellaneous employees. The second measure subtracts the share of administrative workers and clerks. Source: Current Population Surveys, and Philippon and Resheff (2007). 


\section{Figure 5: Investment Shares of Low Cash Firms}

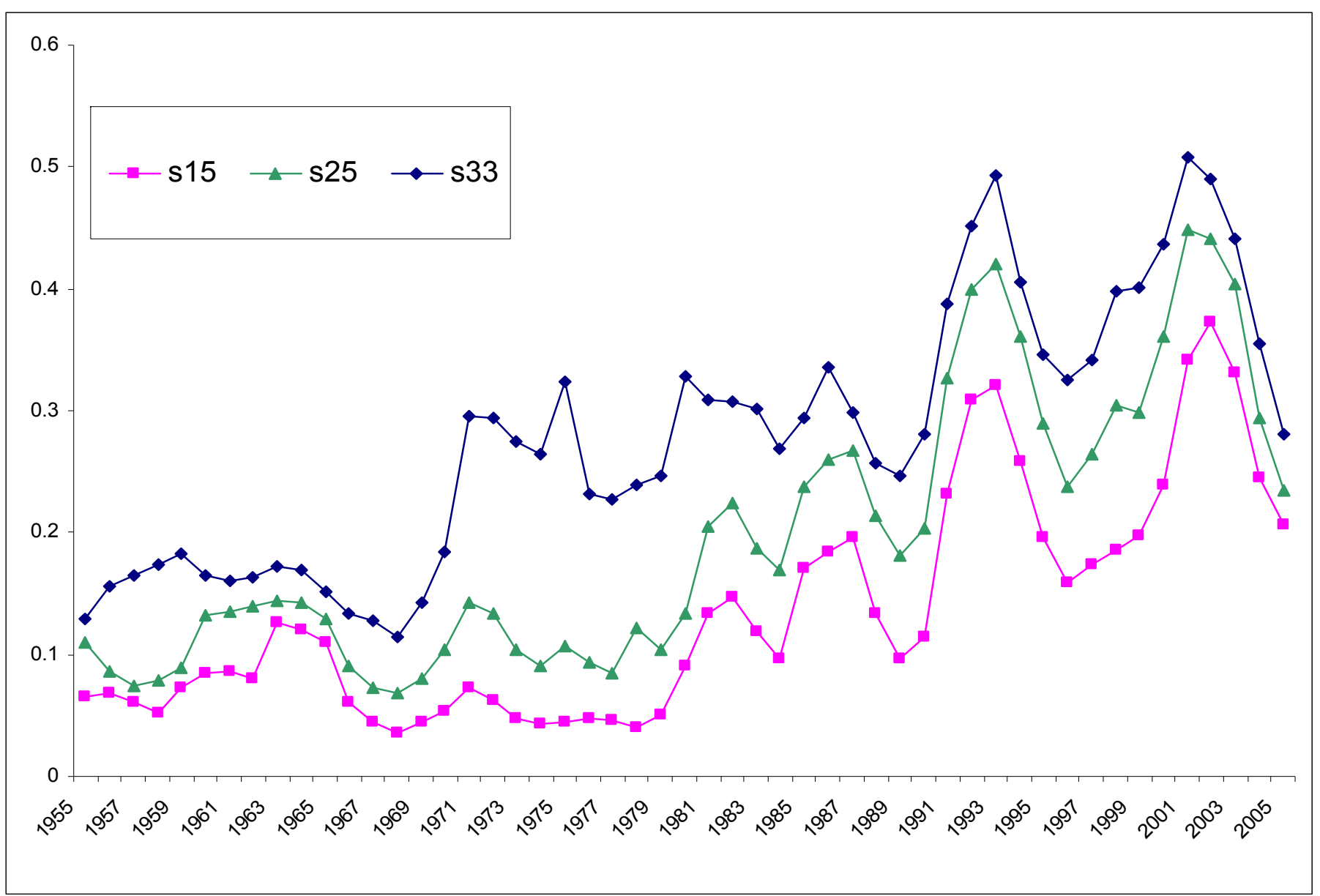

Notes: Sum of capital expenditures by firms whose income is less than $15 \%, 25 \%$ or $33 \%$ of their capital expenditures, divided by the sum of capital expenditures by all the firms in the sample. Source: Compustat, industrial firms, excluding finance and real estate. 
Figure 6: Equilibrium Without Moral Hazard

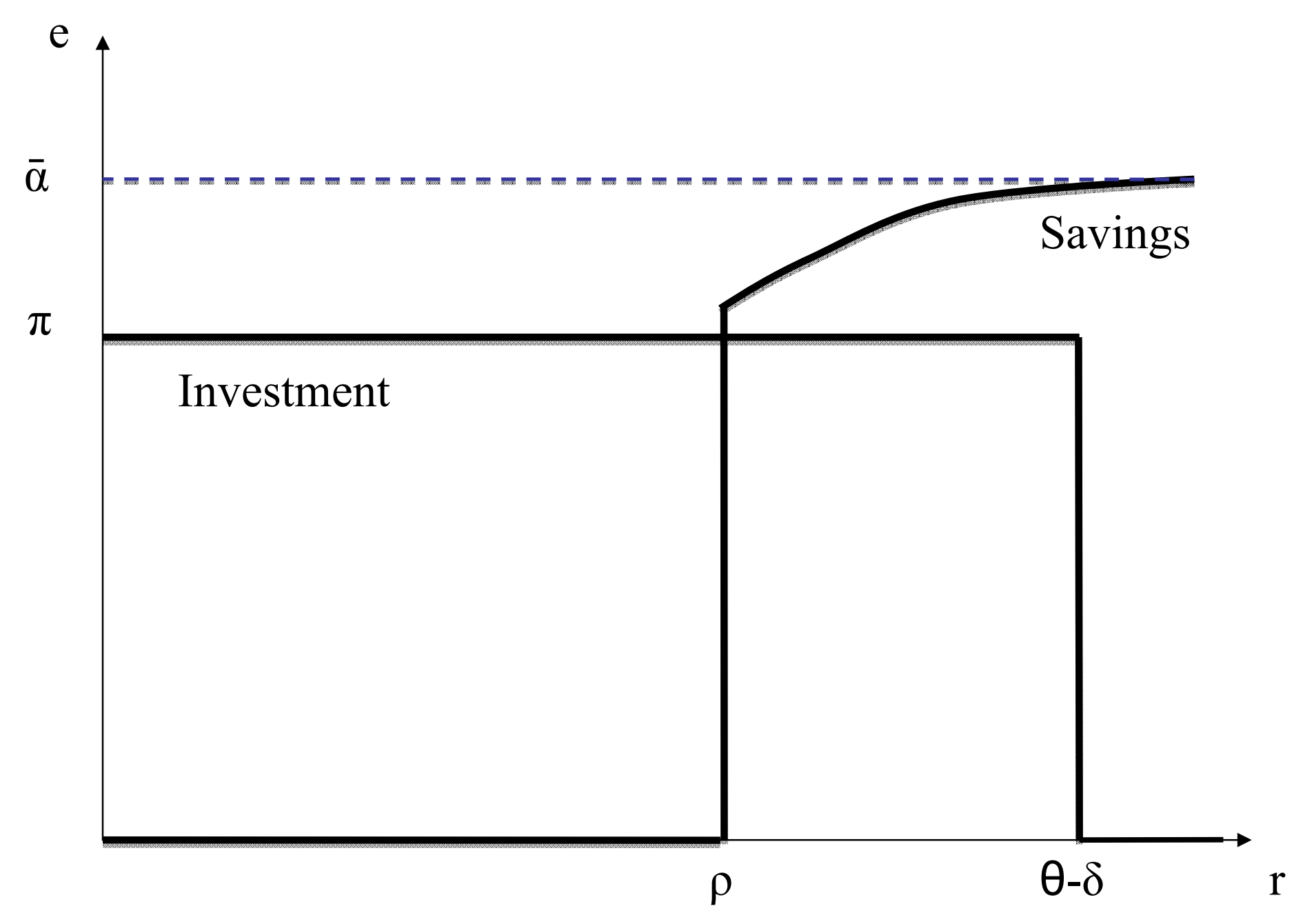


Figure 7: Equilibrium With Moral Hazard

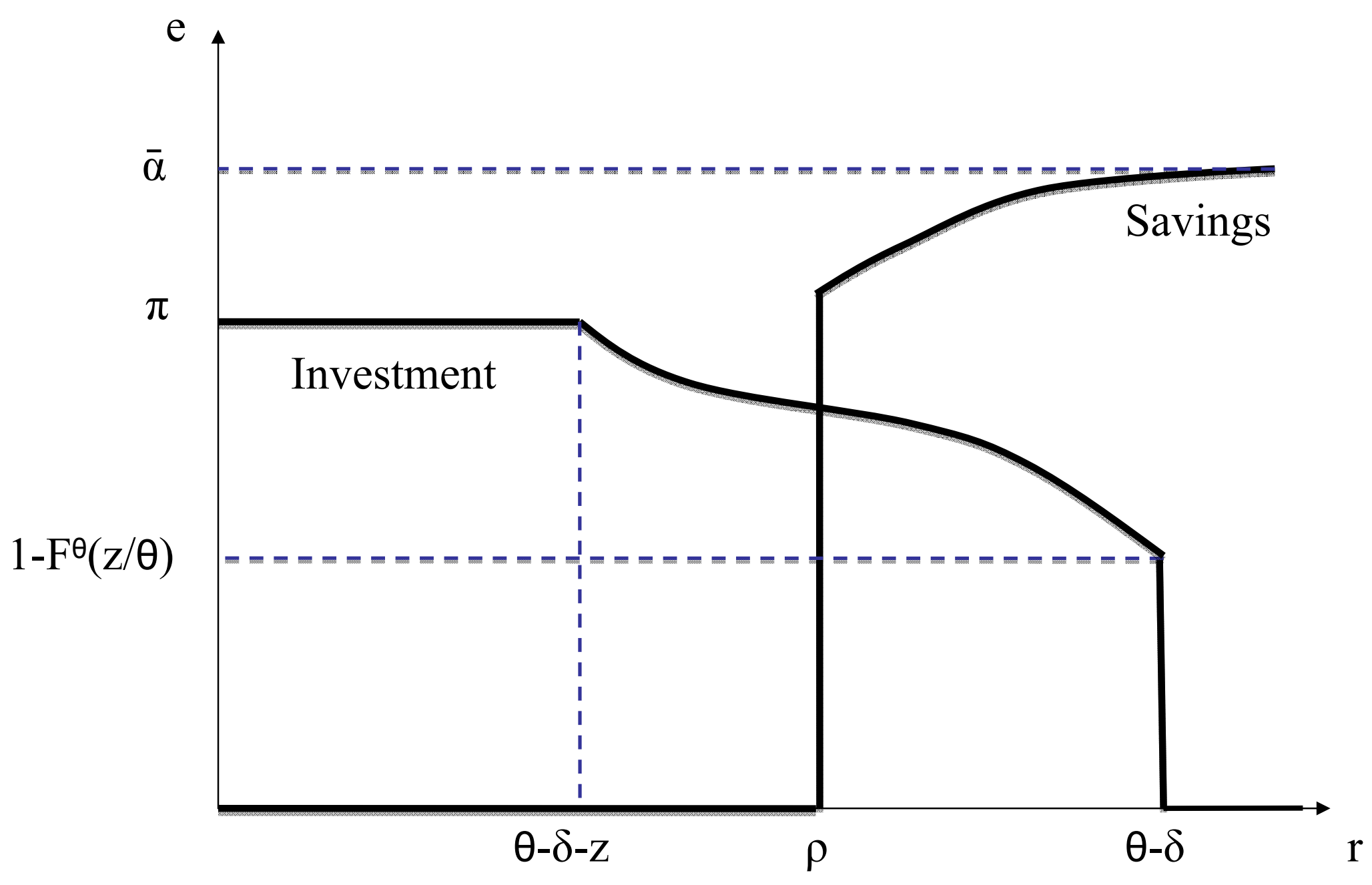




\section{Figure 8: Equilibrium With Monitoring}
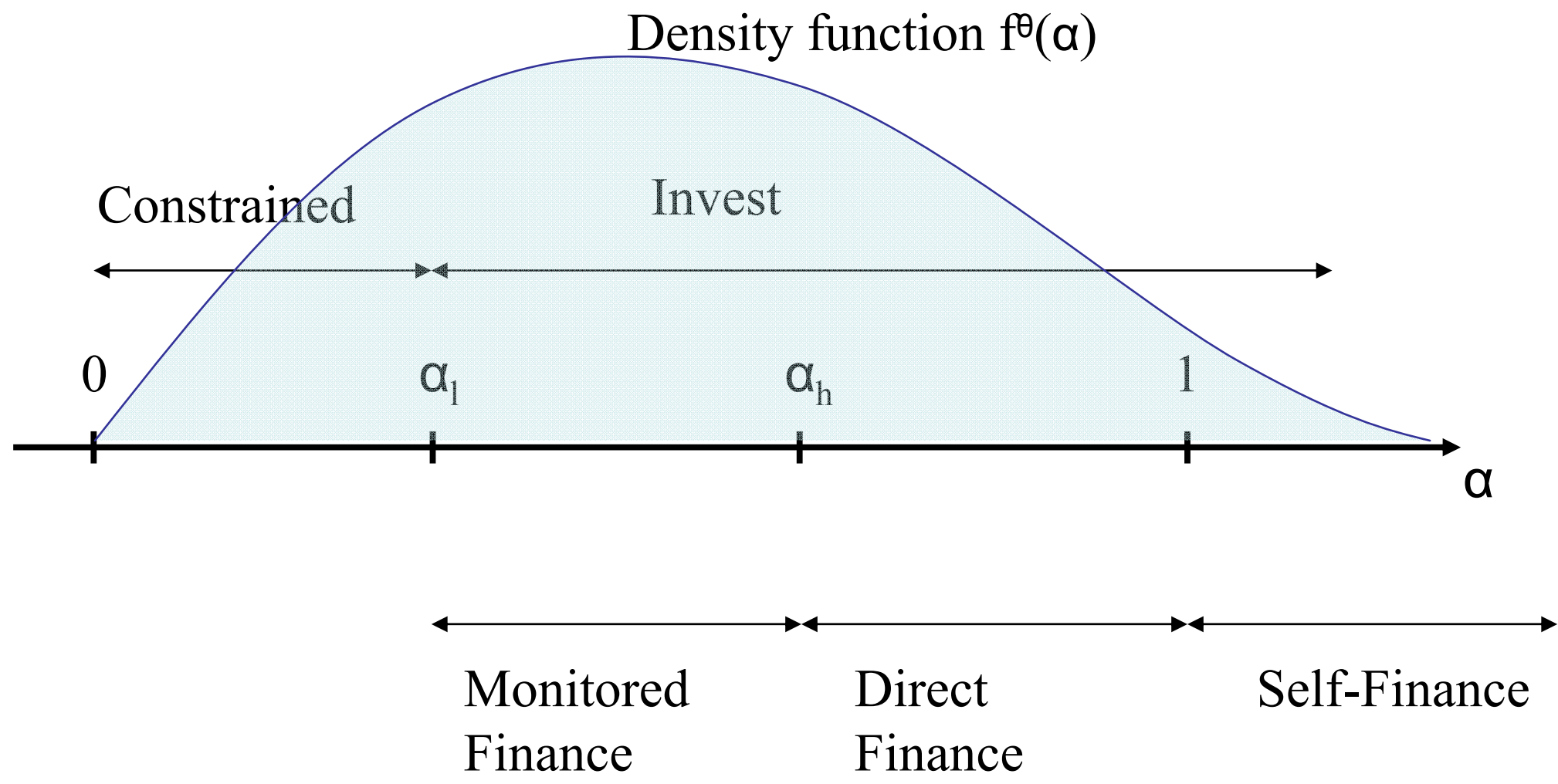


\section{Figure 9: Simulation of Calibrated Model}

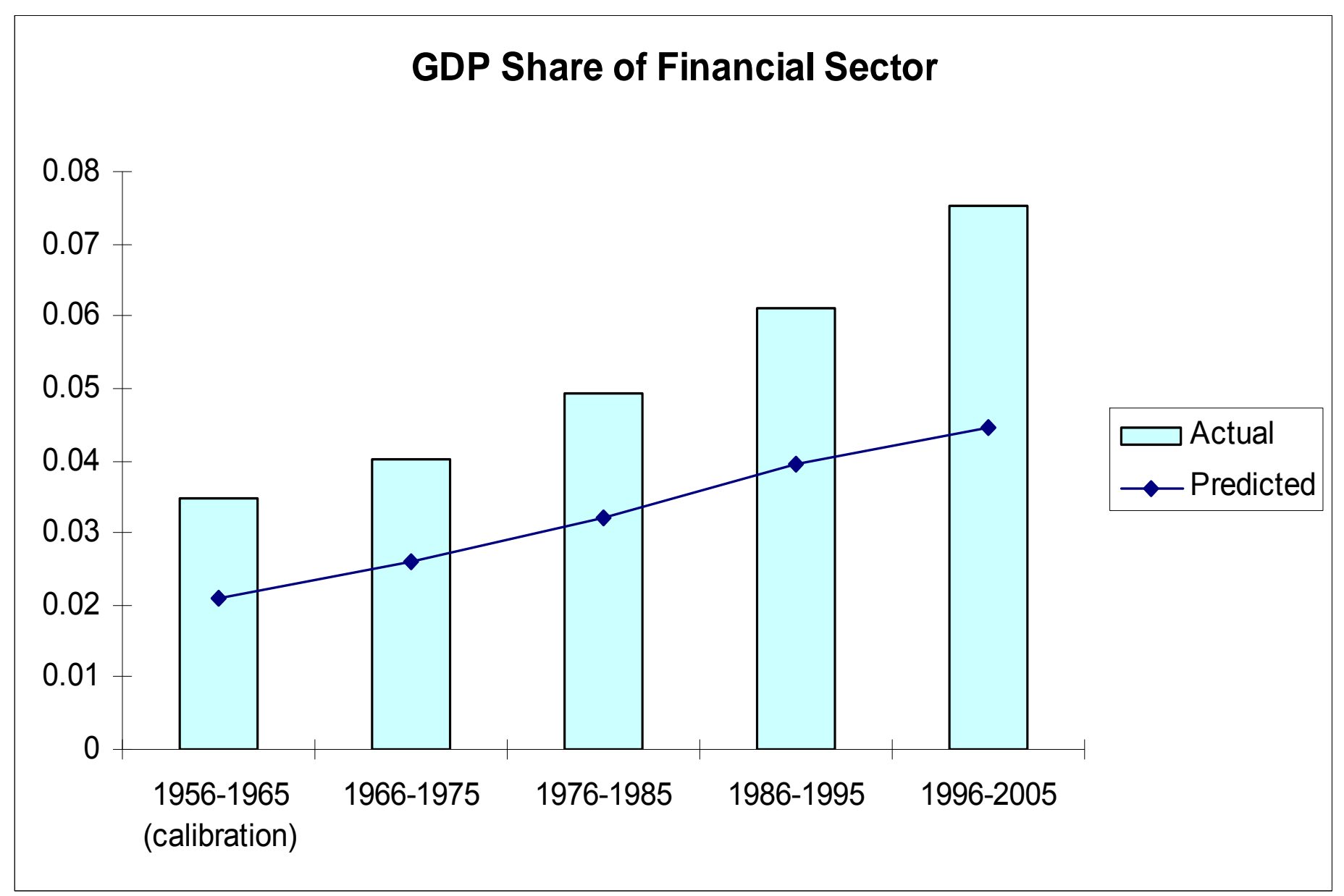

Notes: The predicted share is based on corporate financial services only. It is constructed with the calibrated model, using the investment to GDP ratio and the cross sectional distribution of cash flows and capital expenditures. 


\section{Figure 10: Simulation of Calibrated Model}

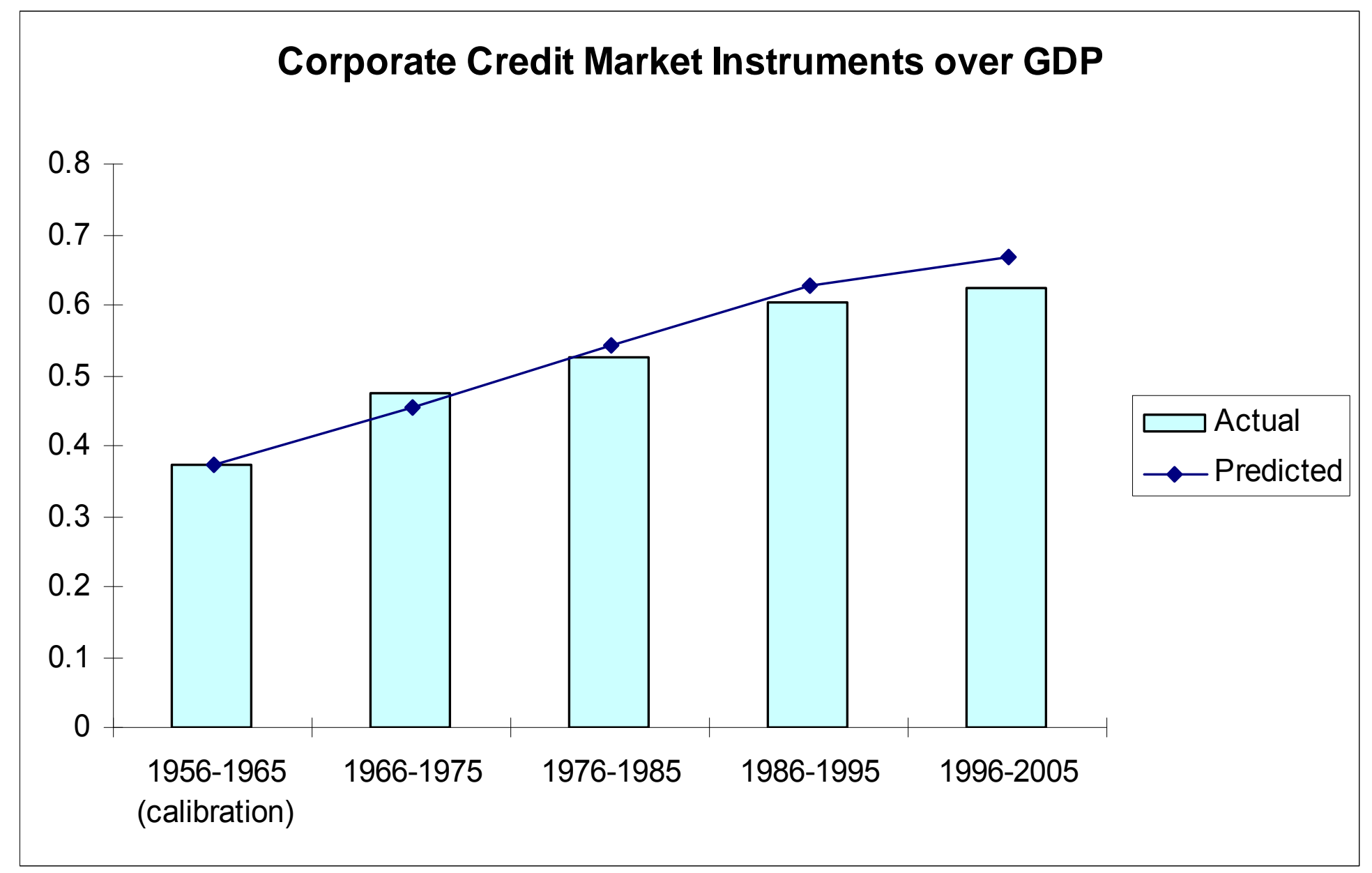

